\title{
Histological Analysis of the Mechanisms of Chattonella-Induced Hypoxemia in Yellowtail ${ }^{\dagger}$
}

\author{
Atsushi Ishimatsu, ${ }^{* 1, \dagger \dagger}$ Mamoru Sameshima, ${ }^{* 1, \dagger \dagger}$ Akihiko Tamura, ${ }^{* 1}$ \\ and Tatsuya Oda*2 \\ ${ }^{*}$ Nomo Fisheries Station, Nagasaki University, Nomozaki, Nagasaki 851-05, Japan \\ ${ }^{* 2}$ Faculty of Fisheries, Nagasaki University, Bunkyo, Nagasaki 852, Japan
}

(Received May 29, 1995)

\begin{abstract}
The effect of Chattonella exposure on gill histology of yellowtail was examined to clarify the following questions: (1) Is the branchial edema, previously reported as the main branchial lesion in response to Chattonella exposure, truly caused by Chattonella cells or a secondary histological alteration by fatal hypoxemia during the exposure? (2) Is the branchial edema responsible for the rapid decline of blood oxygen levels during the early stages of Chattonella exposure? Fish dying from Chattonella exposure showed many types of lesions, especially severe epithelial separation in the lamellae and filaments. In contrast, the gills of fish dying from environmental hypoxia showed very few lesions and were histologically hardly discernible from the control gills. This demonstrated that the branchial edema was induced by Chattonella and not by hypoxemia. On the other hand, the epithelial separation had not developed when the tissues were sampled immediately after the onset of hypoxemia. Therefore, the edema cannot be the cause of hypoxemia. The only histological change observed in the gills sampled at blood oxygen drop was blockade of interfilamental spaces by mucus. Based on these results and the previous findings of oxygen radical production by Chattonella, we hypothesized that oxygen radicals, released from Chattonella cells, stimulated mucus cells in the gills, and the secreted mucus, possibly plus Chattonella cells trapped within the mucus, destroyed the gas exchange capacity of the gills by shunting respiratory water current away from the lamellae.
\end{abstract}

Key words: Chattonella, yellowtail, gill, histology, mucus, edema, epithelial separation

Blooming of toxic phytoplankton species, Chattonella spp., has repeatedly caused massive mortalities of cultured fish, particularly the yellowtail Seriola quinqueradiata, during the last two decades in Japan. ") Suffocation is generally supposed to be the direct cause of the fish death by this plankton species, ${ }^{2-6)}$ although limited information is available regarding the effects of Chattonella on the oxygen transport system of fish. We previously studied the effects of Chattonella on the physiological state of the yellowtail, and concluded that the rapid drop of arterial oxygen partial pressure $\left(\mathrm{PaO}_{2}\right)$ occurring at the early phase of exposure was the likely proximate cause of fish mortality. ${ }^{7-9)}$ However, how Chattonella induce hypoxemia remains unknown.

A few papers have reported histological changes of the gills induced by Chattonella. Shimada et al.$^{10)}$ found the apparent disappearance of mucus cells in the yellowtail gill exposed to C. antiqua. They proposed that the loss of mucus layers impaired osmoregulatory function. The resultant osmotic imbalance would lead to edema formation which in turn reduces the gas exchange capacity of the gills. Subsequently, Toyoshima et al. ${ }^{11)}$ observed that $C$. antiqua caused histological alterations of chloride cells in the yellowtail gill. They also related the finding to edema formation. However, the cause-and-effect relationship be- tween these histological and physiological findings has never been ascertained. There are two unanswered questions that we think are crucial in considering the mechanisms of fish kill by Chattonella. First, it is not entirely clear if the observed histological changes are truly attributable to the direct effect of Chattonella exposure, or induced secondarily by fatal hypoxemia. Second, it is not known if the branchial edema is truly responsible for the drop of blood oxygen levels during Chattonella exposure.

The present study was designed to clarify the above two questions. To answer the first question, we compared the gills of fish dying from Chattonella exposure and environmental hypoxia. The second question was investigated by taking gill tissue samples from chronically cannulated yellowtail as soon as $\mathrm{PaO}_{2}$ started to decline after the onset of Chattonella exposure. If the branchial edema does cause hypoxemia, then the edema must be present when $\mathrm{PaO}_{2}$ is lowered during the exposure (sometimes within $15 \mathrm{~min}$, see Tsuchiyama et al. $\left.{ }^{97}\right)$. Speare and Ferguson ${ }^{12)}$ demonstrated that artifacts like epithelial separation (an histological manifestation of edema) can quickly develop in fish gill, depending on sampling methods and fixatives used. Great care was therefore taken to preserve the histology of the gills at the moment of sampling.

The results demonstrated that (1) epithelial separation

\footnotetext{
Contribution from Nomo Fisheries Station, Nagasaki University, No. 138.

tt Send reprint requests to: Dr. Atsushi Ishimatsu, Nomo Fisheries Station, Nagasaki University, Nomo 714, Nomozaki, Nagasaki 851-05, Japan.

+IT Present address: Kumamoto Prefectural Fisheries Research Center, Ohyano 2450-2, Amakusa, Kumamoto 869-36, Japan.
} 
and other morphological changes, observed in fish dying from Chattonella exposure, were clearly induced by Chattonella and not by severe hypoxemia. More importantly, (2) these changes were not observed at the time of $\mathrm{PaO}_{2}$ drop and cannot therefore be the cause of hypoxemia. The only histological alteration detectable at the time of $\mathrm{PaO}_{2}$ drop was a considerable accumulation of mucus between the filaments and lamellae. Based on these findings, we propose blockade of the respiratory flow through the gills by mucus to be the main mechanism for the rapid depletion of blood oxygen during the early phase of Chattonella exposure.

\section{Materials and Methods}

\section{Experimental Fish}

Fish used in this study were mostly obtained from a local aquaculturist, but some fish used in experiment 2 were also kindly offered by Aquaculture Laboratory, Nagasaki Prefectural Institute of Fisheries. No distinction was made between the fish from the two sources. Fish were maintained in net pens and fed minced sardines every other day. Two days before the experiments, fish were transferred to a 1,000 $l$ indoor tank and kept without feeding as previously described. ${ }^{7)}$ Sea water temperature was kept at $25 \pm 1{ }^{\circ} \mathrm{C}$. Means and standard errors (S.E.) of body weights were $276 \pm 14 \mathrm{~g}$ for experiment 1 and $1,134 \pm 73 \mathrm{~g}$ for experiment 2 (see below), respectively.

\section{Plankton Culture}

Chattonella sp. isolated in Kumamoto in 1990 were used in experiment 1. Chattonella marina isolated in Kagoshima in 1985 were used in experiment 2. Both strains were batch-cultured using ESM medium (Erd-Schreiber modified; $\mathrm{NaNO}_{3} 120 \mathrm{mg}, \mathrm{K}_{2} \mathrm{HPO}_{4} 5 \mathrm{mg}$, vitamin $\mathrm{B}_{12} 1 \mu \mathrm{g}$, biotin $1 \mu \mathrm{g}$, thiamine $\mathrm{HCl} 100 \mu \mathrm{g}$, Fe-EDTA $259 \mu \mathrm{g}$, MnEDTA $332 \mu \mathrm{g}$, Tris (hydroxymethyl) aminomethane $1 \mathrm{~g}$, soil extract $50 \mathrm{~m} l$, sea water $950 \mathrm{ml}, \mathrm{pH} 8.0$ ) as previously described." These two strains showed the same growth characteristics, morphology and toxicity to yellowtails.

\section{Experimental Protocols}

\section{Experiment 1}

This experiment was designed to investigate whether the gill lesions previously reported during Chattonella exposure (see Introduction) were truly caused by the algae or by hypoxemia. For this purpose, we compared the gill histology of fish dying from Chattonella exposure and from environmental hypoxia. Fish were transferred to 100 $l$ polycarbonate tanks with flow-through sea water supply $12 \mathrm{~h}$ before the experiments. Each tank contained six fish. Sea water supply was stopped immediately before the experiments. The fish were subjected to the following three treatments. To the first tank, 10 liters of ESM medium was added at the onset of an experiment (control). To the second tank, 10 liters of Chattonella-containing medium (approximately 40,000 cells $/ \mathrm{ml}$ ) were added to attain a final cell concentration of 4,000 cells $/ \mathrm{m} l$. Cell concentration was determined at 10,30 , and 60 min by counting cell numbers under a microscope. Dissolved oxygen levels of these two tanks were maintained at near saturation levels by bubbling the water with pure oxygen. To the third tank, 10 liters of ESM medium was also added, and dissolved oxygen level was lowered by nitrogen bubbling such that the time to death by the treatment was comparable to that in the Chattonella-exposed group. Fish were killed by a sharp blow on the head when they were moribund (the Chattonella-exposed and the hypoxia groups) or at the end of an experiment $(8 \mathrm{~h}$, control). The first gill arch on the left side was immediately cut, rinsed in diluted isotonic sea water, and fixed in Bouin's fixative. The time from killing to fixation was less than $20 \mathrm{~s}$. Samples were discarded if sampling was delayed. Water temperature was kept at $25 \pm 1{ }^{\circ} \mathrm{C}$. Light intensity was 5,000 to $8,000 \mathrm{~lx}$. Water $\mathrm{pH}$ was adjusted to 8.2 by adding $0.1 \mathrm{~N} \mathrm{NaOH}$ when necessary.

\section{Experiment 2}

This experiment was designed to clarify the gill histology of the fish when blood oxygen level was lowered by Chattonella exposure. Fish used in this experiment $(\mathrm{N}=6$ for both control and Chattonella-exposed groups) were anesthetized and fitted with chronic dorsal aortic cannulae as previously described. ${ }^{7}$ Fish were allowed to recover for $24 \mathrm{~h}$ in a darkened Plexiglass chamber continuously supplied with sea water (for the details of the setup used in experiment 2, see Ishimatsu et al. $\left.^{7}\right)$ ). Water temperature was kept at $25 \pm 1^{\circ} \mathrm{C}$ as above. For control, gills were sampled after blood gas measurements under resting conditions. Fish were quickly lifted out of the chamber with the aid of a plastic net placed inside it and killed by piercing the cranium with an eyeleteer. The heart was cut to prevent contamination of the gills with blood. The first gill arch on the left side was trimmed off and immediately placed in Bouin's fixative without rinsing. The time after fish removal from the chamber to fixation was within $20 \mathrm{~s}$. Samples were discarded when sampling was delayed or the gills were covered with excessive amounts of blood. Chattonella exposure was conducted using the same protocol as previously described. ${ }^{7}$ Plankton concentration was kept at 4,000 cells $/ \mathrm{m} l$. Gills in this group were sampled when $\mathrm{PaO}_{2}$ fell below $30 \mathrm{mmHg}$, at which value secondary physiological disorders became manifest during Chattonella exposure. ${ }^{\text {? }}$ The $\mathrm{PaO}_{2}$ and arterial $\mathrm{pH}(\mathrm{pHa}$ ) were measured by an IL213 blood gas analyzer (Instrumentation Laboratory, Mass.) thermostatted to $25^{\circ} \mathrm{C}$.

\section{Morphometric Evaluation}

1. Experiment 1

The gills were fixed in Bouin's solution for 15 to $17 \mathrm{~h}$, transferred to $80 \%$ ethanol, and left for 26 to $50 \mathrm{~h}$. They were then placed in 5\% EDTA (pH 7.0) for $24 \mathrm{~h}$ for decalcification, dehydrated, and embedded in paraffin. Sections ( $4 \mu \mathrm{m}$ thick) were made on a plane parallel to the long axis of the filament and perpendicular to the surface of the filament (plane 1). These were then stained with hematoxylin and eosin. Six middle portions of five to six filaments were randomly chosen for each fish, photographed with an Olympus light microscope, and analyzed for the following types of lesions. Epithelial separation (intraepithelial edema) of the secondary lamellae was defined after Speare and Ferguson ${ }^{12)}$ and Skidmore and Tovell. ${ }^{13)}$ The extent of epithelial separation was semi-quantified as follows. First, the ratio of epithelial portion where the epithelium was separated from the underlying basal lamina-pillar cell com- 
plex to the total perimeter of a lamella was calculated. Second, percentage frequencies of the lamellae with less than $5 \%, 5-20 \%, 20-80 \%$ and higher than $80 \%$ of epithelial separation were calculated for each fish. The part where the epithelium was lost (epithelial rupture) was included in this category (epithelial separation), but was also assessed independently. The extent of epithelial rupture was expressed as the ratio of the number of the lamellae which showed this type of lesion to the total number of lamellae observed. Erythrocyte numbers in the secondary lamellae were estimated by counting the number of nuclei in a section as an index for branchial congestion. Hypertrophy and hyperplasia were evaluated according to Speare and Ferguson, ${ }^{12)}$ and their extent was evaluated as for epithelial rupture. Mean values of these morphometric parameters were obtained for each fish, and overall means and S.E.s (means and S.E.s of the individual mean values) were calculated. Numbers of lamellae analyzed were 1,027 from 6 fish in the control, 835 from 5 fish in the Chattonella-exposed group, and 769 from 5 fish in the hypoxia group.

\section{Experiment 2}

Sectioning was made on three planes in this experiment. Plane 1 was the same plane as in experiment 1 . Plane 2 was perpendicular to both the long axis of the filament and the surface of the filament (cross section of the filament). Plane 3 was parallel to both the long axis of the filament and the surface of the primary filament. Middle portions of 36 filaments taken from the middle part of the gill arches were analyzed in plane 1 for each fish. Sections cut in plane 2 were stained with either Alcian blue and the periodic acid-Schiffs reagent (PAS) or Alcian blue, PAS, hematoxylin and eosin, and used to observe mucus cells on the afferent (trailing) and efferent (leading) edges of the filament and mucus substances secreted from the cells ( 44 to 50 filaments and interfilamental spaces were observed for each fish). We defined mucus blockade of interfilamental spaces as the state where mucus spans the full distance between the neighboring filaments when viewed in plane 2 . Ratios of the number of interfilamental spaces blocked by mucus to the total number of spaces observed were calculated for both the afferent and efferent edges. Those cut in plane 3 were stained with hematoxylin and eosin, and used to observe adductor and abductor muscles and the afferent and efferent filamental arteries at their origins from the branchial arteries. The extent of epithelial separation and erythrocyte number per lamellae were estimated as in experiment 1 .

\section{Statistics}

One-way ANOVA followed by Bonferroni test for pairwise comparison was applied in experiment 1. Bartlett's test was conducted to check the homogeneity of variance. A Student $t$-test or Cochran-Cox test was also performed in experiment 1 and 2 where appropriate. Data are expressed as mean $\pm \mathrm{S}$.E. wherever possible.

\section{Results}

\section{Experiment 1}

All fish in the control group survived $8 \mathrm{~h}$ of experiment and showed no signs of distress. All fish in the Chattonella-exposed group died with a mean death time of
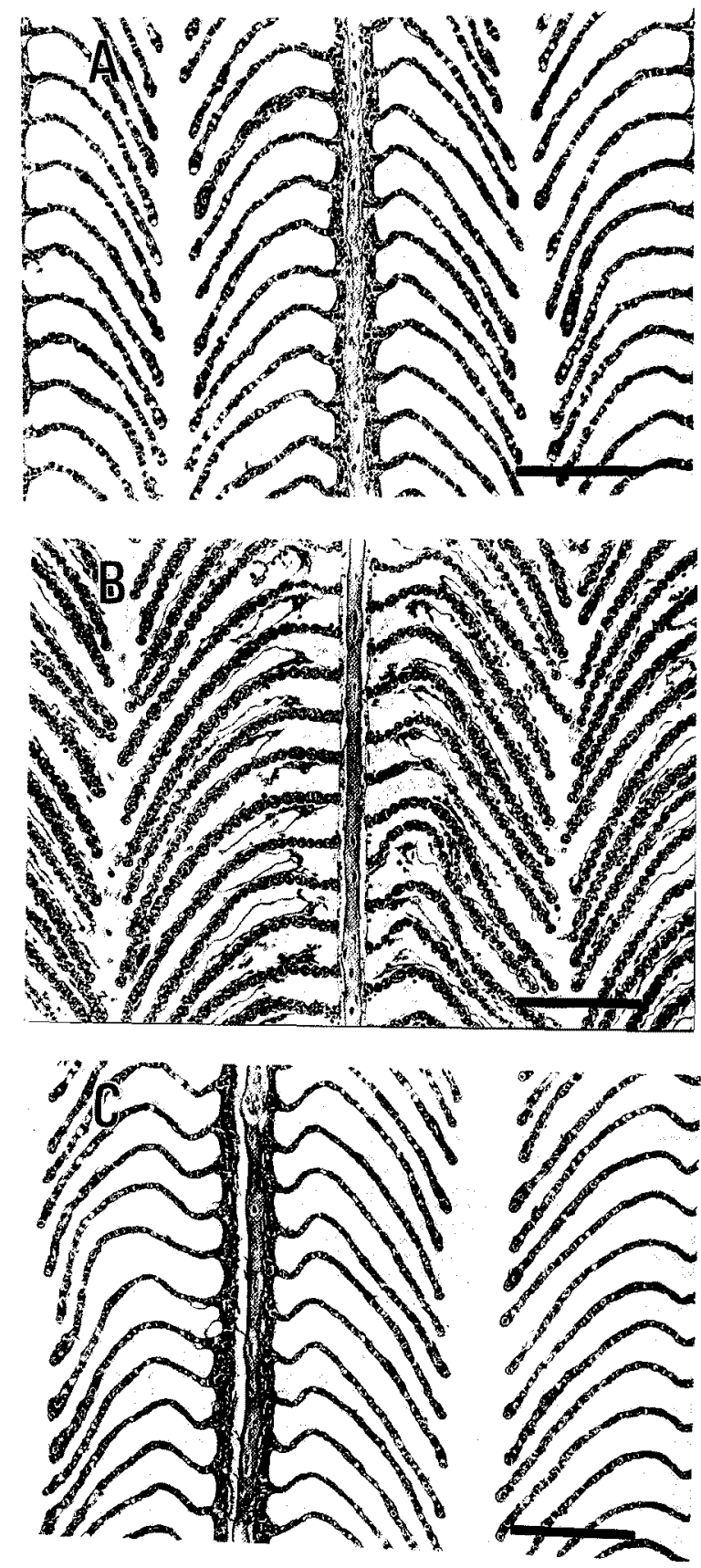

Fig. 1. Gill filaments of yellowtail in the control (A), the Chattonella-exposed group (B), and the hypoxia-exposed group (C) in experiment 1 .

Note a considerable degree of epithelial separation in (B) and its absence in (A) and (C). Gill samples (B) and (C) in this experiment were taken near the death. Bars represent $100 \mu \mathrm{m}$.

$37.0 \pm 5.0 \mathrm{~min}$. Sea water oxygen level in the hypoxia group fell to $50 \%$ of the saturation level at $10 \mathrm{~min}, 25 \%$ at $25 \mathrm{~min}$, and stabilized at $15 \%$ at $60 \mathrm{~min}$ and thereafter. Fish in the hypoxia group died with a mean death time of $44.8 \pm 3.5 \mathrm{~min}$. There was no significant difference between death time of the two groups ( $p>0.05, t$-test).

Figure 1 shows microscopic photographs of the gills sampled in this experiment. A marked difference in gill morphology is obvious between the control (Fig. 1A) and the 
Chattonella-exposed fish (Fig. 1B), while the gills of the hypoxia-exposed fish (Fig. 1C) were quite similar to those of the control. In the Chattonella-exposed fish (Fig. 1B), lesions were not restricted to the lamellae. Filamental epithelium also showed a considerable degree of epithelial separation and most cells in the filamental epithelium, including chloride cells, appeared to be necrotic.

Morphometric analysis supported the above qualitative evaluation between the gills of the three groups. Figure $2 \mathrm{~A}$ compares percentage frequencies of the secondary lamellae that were classified into 4 degrees of epithelial separation between the groups. Apparently, the pattern was similar between the control and the hypoxia groups in that most lamellae showed less than $5 \%$ of separation $(95.4 \pm 0.7 \%$ for the control; $83.7 \pm 6.1 \%$ for the hypoxia group), although there was a moderate increase in the extent of epithelial separation in the latter. In contrast, fish in the Chattonella-exposed group showed a very high incidence $(61.5 \pm 7.2 \%)$ of lamellae with $>80 \%$ of epithelial separation. The distribution pattern of erythrocyte numbers within a lamella in the Chattonella-exposed group was also quite different from those in the control and the hypoxia groups (Fig. 3). Mean erythrocyte numbers were $17.8 \pm 0.6$ cells / lamella in the control and $14.8 \pm 0.6$ in the hypoxia group, whereas lamellae in the Chattonella-exposed group showed a wider distribution pattern ranging from less than 10 to more than 150 cells / lamella. The extent of epithelial rupture in the Chattonella-exposed group $(33.4 \pm 6.5 \%)$ was significantly higher than that in the control $(7.6 \pm 2.7 \%)$ and the hypoxia groups $(2.3 \pm 0.9 \%)$ $(p<0.01$, Bonferroni test). Hypertrophy in the control fish showed a small but significantly higher incidence than in the Chattonella-exposed group ( $p<0.05$, Bonferroni test). There was no significant difference in the extent of hyperplasia between the groups.

\section{Experiment 2}

Arterial oxygen pressure $\left(\mathrm{PaO}_{2}\right)$ rapidly declined after the onset of Chattonella exposure (Fig. 4). Mean time for the $\mathrm{PaO}_{2}$ to decrease to below $30 \mathrm{mmHg}$ was $27.5 \pm 4.6 \mathrm{~min}$ $(\mathrm{N}=6)$. The pHa was not significantly different between the pre-exposure and the last samples $(7.863 \pm 0.017$ for the pre-exposure, $7.844 \pm 0.028$ for the last sample, $p>0.05$, paired $t$-test).

When the gills cut in the plane 1 were compared between the control (Fig. 5A) and the Chattonella-exposed groups (Fig. 5B), they appeared almost indistinguishable from each other, if it were not for Chattonella cells occasionally trapped between the filaments or lamellae in the latter group. The gills of the control fish showed low occurrence of lesions, indicating that the cannulation procedure only minimally affected the gill histology of these fish (cf. Figs. $1 \mathrm{~A}$ and $5 \mathrm{~A}$ ). The percentage frequency of lamellae with epithelial separation in the control fish in this experiment was higher than that of the control fish in experiment 1 , but lamellae with less than $5 \%$ of separation still occupied $82.0 \pm 4.3 \%$ of the total (Fig. 2B). The lamellae of the Chattonella-exposed fish sampled at the time of $\mathrm{PaO}_{2}$ drop showed an almost identical pattern of percentage frequency of epithelial separation to that in the control fish of this experiment (Fig. 2B). There was no significant difference in erythrocyte number within a lamella between the groups (22.6 2.1 for control and $21.9 \pm 2.3$ for Chattonella-exposed, $p>0.05, t$-test). Epithelial rupture, hypertrophy and nuclear pyknosis were seldom observed in the gills of the two groups. There were no apparent lesions in both the abductor and adductor muscles in the gills of the Chattonella-exposed group, nor was there any abnormality (vasoconstriction or vasodilation) observed in the filamental arteries at their basal portions.

A marked difference in gill morphology was evident
(A)

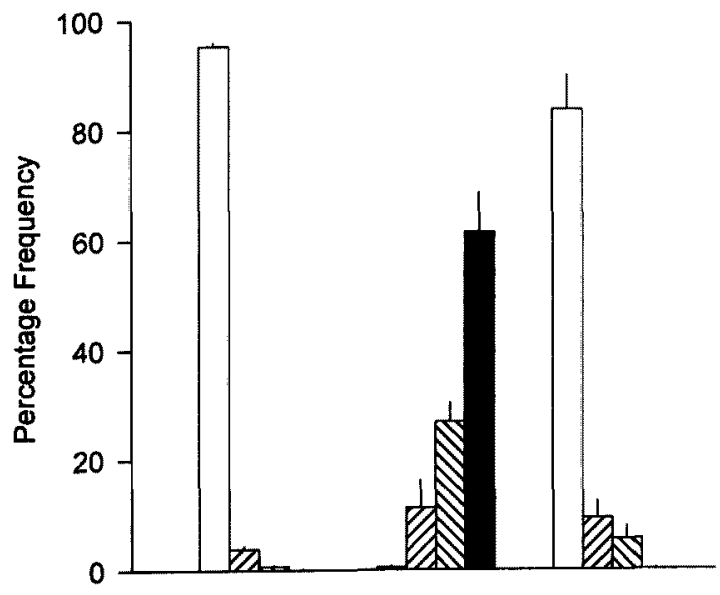

(B)

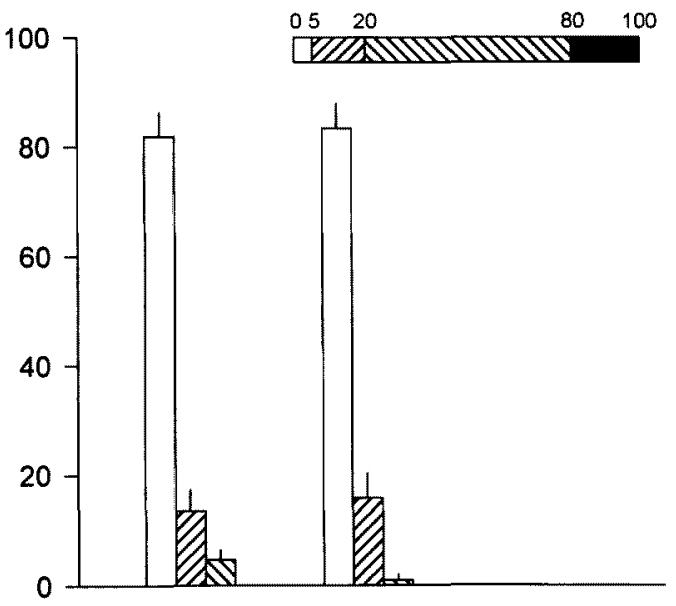

Control Chattonella Hypoxia

Control Chattonella

Fig. 2. A comparison of percentage frequencies of the secondary lamellae showing epithelial separation in less than $5 \%, 5-20 \%, 20-80 \%$, and higher than $80 \%$ of the total perimeter of a lamella in experiment 1 (A) and experiment 2 (B).

Vertical bars represent S.E. N is 6 for the control, 5 for the Chattonella-exposed and the hypoxia-exposed groups in experiment 1 , and is 6 for both the control and the Chattonella-exposed groups in experiment 2 . For details, see the text. 


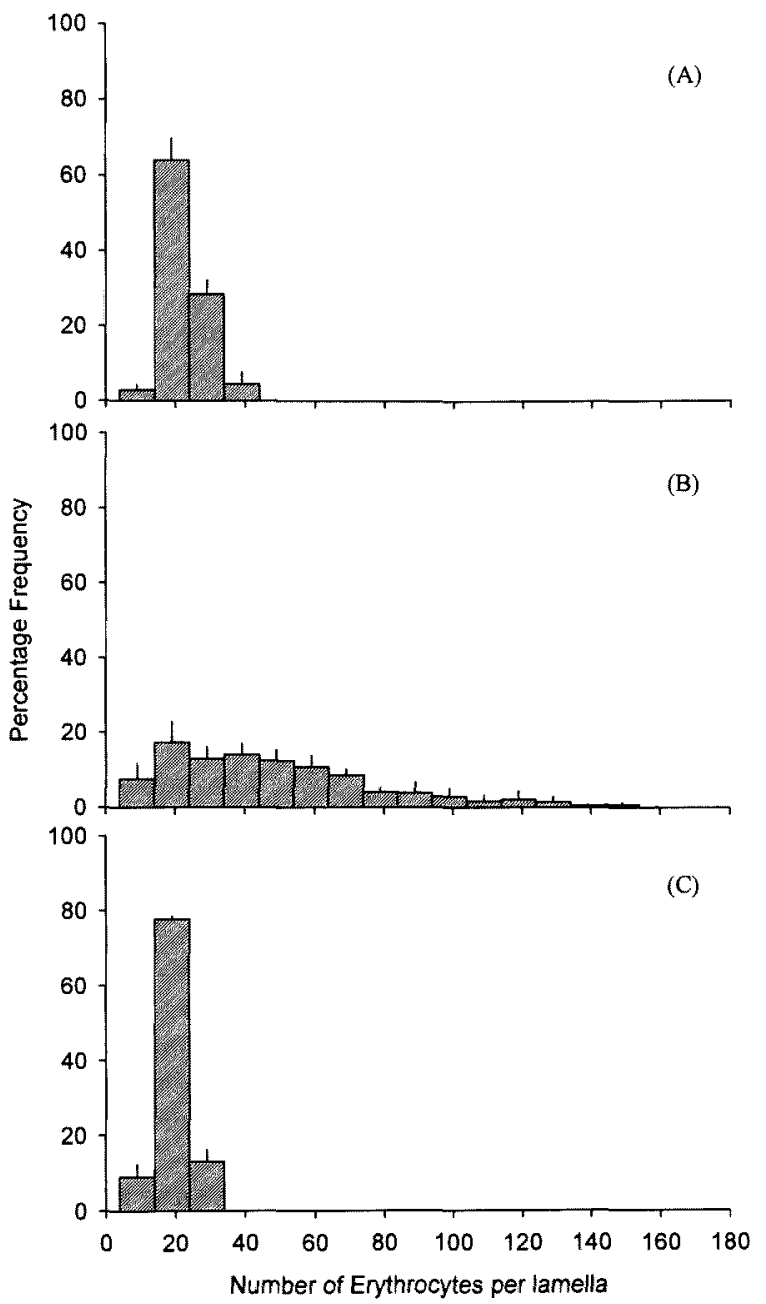

Fig. 3. Histograms of erythrocyte numbers per lamella in the control (A), the Chattonella-exposed (B) and the hypoxia-exposed groups (C) (experiment 1).

Vertical bars represent S.E. $\mathrm{N}$ is 6 for the control, 5 for the Chattonella-exposed and the hypoxia-exposed groups. For details, see the text.

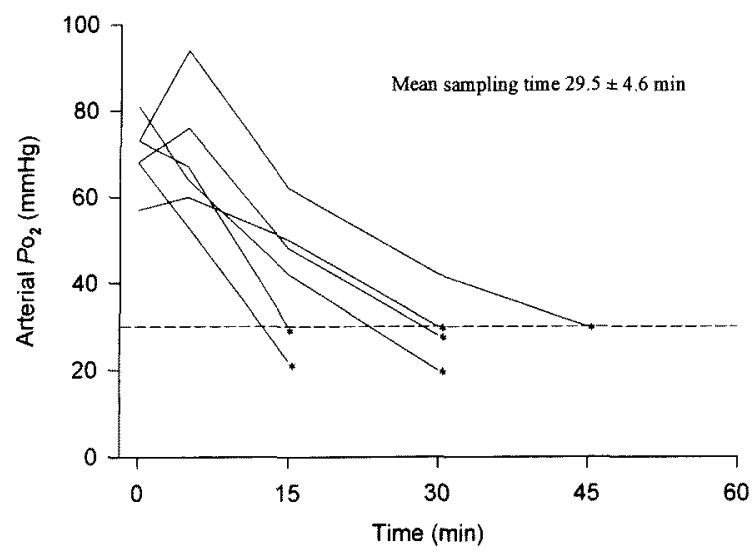

Fig. 4. Changes in arterial $\mathrm{PO}_{2}$ during Chattonella exposure in experiment 2.

Gills were sampled when arterial $\mathrm{PO}_{2}$ fell below $30 \mathrm{mmHg}$ (marked by asterisks).
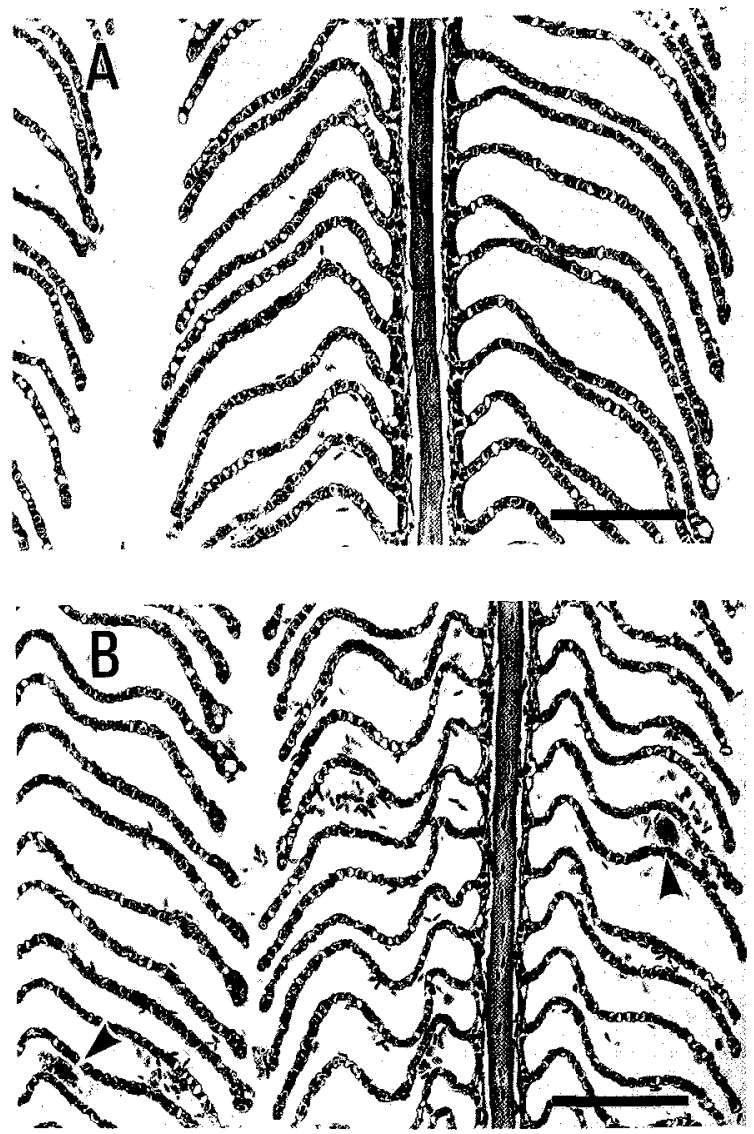

Fig. 5. Gill filaments of yellowtail in the control (A), and the Chattonella-exposed group (B) in experiment 2 .

Gill samples of the Chattonella-exposed group were taken as soon as the arterial $\mathrm{PO}_{2}$ fell to $30 \mathrm{mmHg}$. Arrowheads indicate Chattonella cells. Note the absence of epithelial separation in (B). Bars represent $100 \mu \mathrm{m}$.

when the gills cut in plane 2 were compared between the groups (cf. Fig. 6A for the control and Fig. 6B for the Chattonella-exposed fish). Frequent blockade of the interfilamental spaces was found in the gills of the Chattonella-exposed fish, whereas less occurrence of blockade was evident in the control gill. Table 1 compares the occurrence of mucus blockade of the interfilamental spaces in the control and the Chattonella-exposed fish. More than $50 \%$ of the interlamellar spaces on the afferent side were blocked by mucus in three fish in the Chattonella-exposed group. The other three fish showed 3,35, and $49 \%$. Three control fish showed no incidence of mucus blockade on the afferent side at all, two fish showed $20-30 \%$, and a value of $76 \%$ was found in one fish. In contrast, there were mostly less than $10 \%$ of mucus blockade on the efferent side in both the control and the Chattonella-exposed fish. Chattonella cells were occasionally trapped within the mucus (Fig. 6C), although we did not quantitatively analyze the gill samples in this respect.

\section{Discussion}

\section{Critiques of the Technique}

Histological analysis should form an integral part of the 

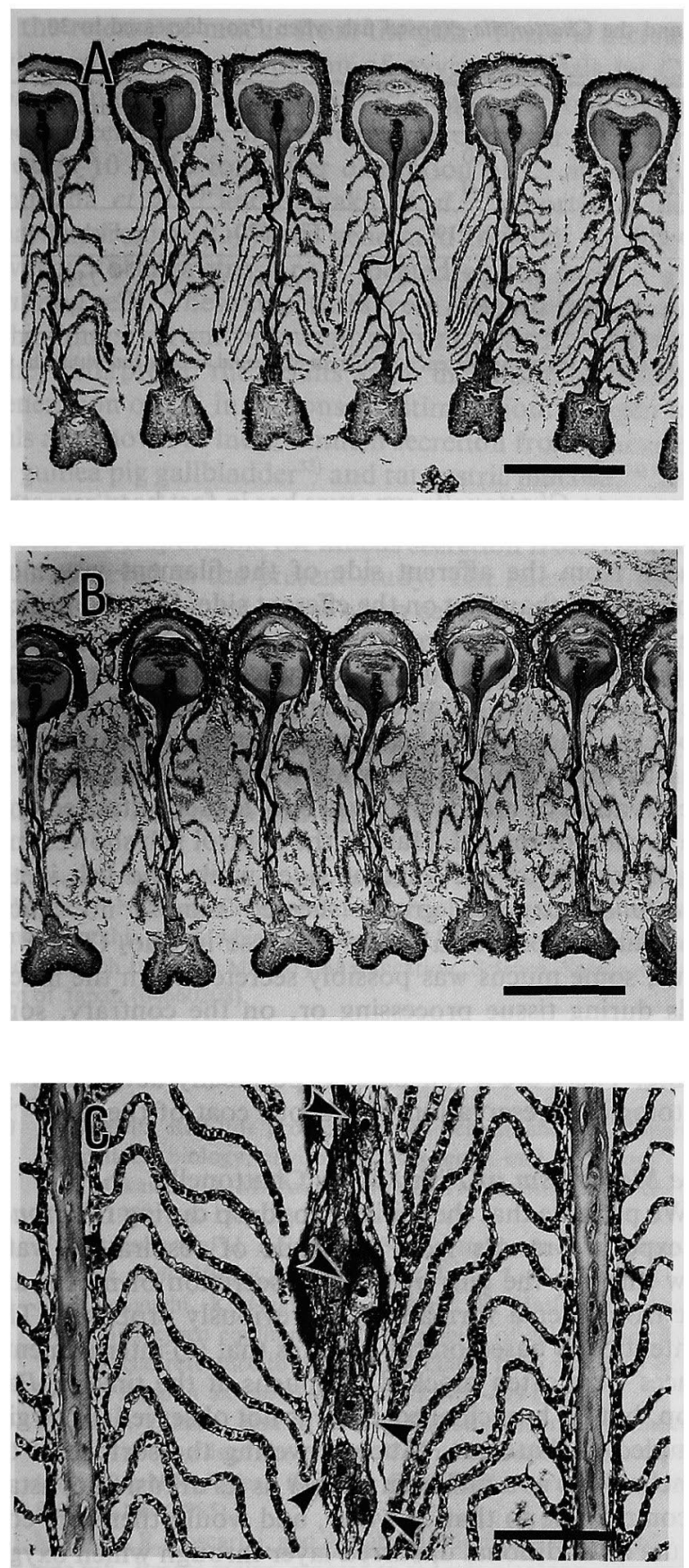

Fig. 6. Cross sections of yellowtail gill filaments obtained in the control (A) and the Chattonella-exposed group (B) in experiment 2.

Note that mucus blocked interfilamental spaces on the afferent side in (B). Micrograph (C) shows several Chattonella cells (arrowheads) in a mass of mucus trapped between the filaments of the Chattonella-exposed group in experiment 2. Bars represent $500 \mu \mathrm{m}$ in (A) and (B), and $100 \mu \mathrm{m}$ in (C).

investigation of the mechanisms of fish kill by Chattonella. Several investigators therefore reported histological changes induced in fish gills by Chattonella exposure (see Introduction for references). The mechanisms of fish kill may not be easily postulated from the results of these histological studies because of the following two uncertainties. First, a detailed account was not always given as to the method of sample processing, and it is known that fish gills easily incur artifactual alterations. ${ }^{12-15)}$ Epithelial separation is the most commonly observed histological change, but it seems possible that the reported frequent occurrence of epithelial capillary separation is possibly due to poor handling of the samples. Second, the timing of tissue sampling has never been related to physiological measurements.

In the present study, we treated the samples in a strictly consistent way, keeping the delay from killing the animals to fixing to less than $20 \mathrm{~s}$. Epithelial capillary separation and other types of lesions were observed with only a low percentage in the control samples of experiment 1 , indicating that artifacts were kept minimal, if any (Fig. 2A). Speare and Ferguson ${ }^{12)}$ also demonstrated that if the time delay between killing the fish and fixation was set to $20 \mathrm{~s}$, epithelial separation and other types of lesions rarely occurred. The cannulation procedure also did not affect gill histology to any extent (cf. Fig. 2A and 2B, see also Figs. $1 \mathrm{~A}$ and $5 \mathrm{~A}$ ). We did not find frequent lamellar dilation as reported for trout killed by a sharp blow on the head or decapitation. ${ }^{16}$

\section{Comparison of the Gills in Moribund Chattonella-exposed} and Hypoxia-exposed Fish (Experiment 1)

Striking histological changes were found in fish dying from Chattonella exposure as compared with the control fish (Figs. 1-3). In contrast, the gills of the hypoxia-exposed fish were histologically almost indiscernible from the control gills. These facts indicate that the observed histological alterations by Chattonella were not caused by hypoxic death but by direct influences of the algae.

Extensive epithelial capillary separation and necrosis of both the filamental and lamellar epithelia were consistent with the results of Toyoshima et al. ${ }^{11)}$ where the gill samples were taken immediately alter death. Endo et al. ${ }^{4)}$ also stated that the gills taken from moribund fish that had been exposed to Chattonella at a concentration of 4,000 cells $/ \mathrm{m} l$ for $60 \mathrm{~min}$ showed edema and hypertrophy of the epithelia in many secondary lamellae. We also noticed numerous necrotic chloride cells as reported by Toyoshima et al. ${ }^{11)}$ Thus, our results on the Chattonella-exposed fish in experiment 1 were generally in good agreement with those previous findings in this respect. These lesions were clearly caused by Chattonella, although their significance in fish kill mechanism by the algae remains unclear. Soivio and Tuurala ${ }^{17)}$ found that environmental hypoxia induced vascular distention, shortening of diffusion distance and swelling of red blood cells in rainbow tout. Branchial lesions as found in the Chattonella-exposed fish in experiment 1 were absent from the trout gills. Secondary lamellae of the hypoxic yellowtail appeared to be thinner than the control ones, though resolution of our light microscopic observation precluded a definite statement (Fig. 1). A marked difference was also observed for red blood cell count per lamella (Fig. 3). Ferguson ${ }^{14)}$ ascribed aneurysm of the lamellae to acute gill injury from chemical or physical trauma. It is conceivable that the lamellar engorgement resulted from cardiovascular disorder that developed toward the death. ${ }^{\text {) }}$

Morphology of the Gills at the Time of $\mathrm{Po}_{2}$ Decline (Ex- 
Table 1. Mucus blockade of the interfilamental spaces in the control and the Chattonella-exposed fish when $\mathrm{PaO}_{2}$ decreased to 30 $\mathrm{mmHg}$ (Experiment 2)

\begin{tabular}{|c|c|c|c|c|c|c|}
\hline Control & Fish \#4 & Fish \#5 & Fish \#8 & Fish \#9 & Fish \#24 & Fish \#25 \\
\hline Afferent side & 0.0 & 0.0 & 75.6 & 0.0 & 29.2 & 21.1 \\
\hline Efferent side & 0.0 & 0.0 & 0.0 & 0.0 & 2.0 & 10.5 \\
\hline Chattonella-exposed & Fish \#16 & Fish \#17 & Fish \#18 & Fish \#19 & Fish \#20 & Fish $\# 23$ \\
\hline Afferent side & 35.2 & 95.2 & 2.8 & 66.1 & 48.4 & 75.0 \\
\hline Efferent side & 7.1 & 12.8 & 0.0 & 4.4 & 6.7 & 3.7 \\
\hline
\end{tabular}

Values represent percentages of blocked interfilamental spaces. Afferent and efferent sides are the side where the afferent and efferent filamental arteries run within the filament, respectively,

\section{periment 2)}

In sharp contrast to the gill histology found in the Chattonella-exposed fish in experiment 1 , the gills sampled at the time of $\mathrm{PaO}_{2}$ decline were almost indistinguishable from the control gills (Fig. 5). There was a very low incidence of epithelial separation and other types of histological alterations. Erythrocyte numbers in the secondary lamellae were almost identical between the Chattonella-exposed and the control fish in this experiment. These results clearly indicate that epithelial separation (edema) in the secondary lamellae is not the cause of blood oxygen depletion as previously proposed. ${ }^{10,11}$ Blood oxygen measurements evidenced that the gas exchange capacity of the gills had already been severely impaired at the time of tissue sampling.

Piiper and Scheid ${ }^{18)}$ and Cameron ${ }^{19)}$ theoretically analyzed respiratory gas exchange in fish gills and proposed a number of possibilities that would lower $\mathrm{PaO}_{2}$. These include: (1) a decrease in ambient water $P_{\mathrm{O}_{2}}$, (2) a decrease in mixed venous blood $\mathrm{PO}_{2}$, (3) a decrease in ventilatory flow, (4) an increase in cardiac output, (5) ventilatory shunting, and (6) vascular shunting. The ambient water $\mathrm{PO}_{2}$ was maintained at near saturation level in this study so that this possibility should be discarded. We did not measure mixed venous $\mathrm{PO}_{2}$ in this and previous studies. We also did not measure ventilatory flow rates during Chattonella exposure, but Matsusato and Kobayashi ${ }^{2)}$ reported a preliminary data that showed an increase in ventilatory flow after exposure. Ishimatsu et $a l .^{7)}$ reported a sharp increase in ventilatory pressures, in response to $\mathrm{PaO}_{2}$ decline alter Chattonella exposure. There are no data available as to the effect of Chattonella on cardiac output. The heart rate did not change during the early phase of exposure but decreased toward the death. ${ }^{7}$ Without detailed information about the performance of the gas transport system during Chattonella exposure, it is difficult to speculate how Chattonella impairs the system, although the present finding on gill histology at the time of $\mathrm{PaO}_{2}$ drop may shed some light on this problem.

The only histological difference from the control gills, found at the time of $\mathrm{PaO}_{2}$ decline, was more frequent occurrence of mucus that apparently blocked interfilamental respiratory water channels. If such blockade does occur, a counter-current flow disposition of water and blood that is widely accepted to reside in fish gill should no longer be functional. A high resistance to flow imparted by mucus would shunt water flow away from close contact with the blood in the secondary lamellae. Secretion of mucus in response to Chattonella exposure has in fact been repeatedly reported..$^{2,4,10,20)}$ Shimada et al. ${ }^{10)}$ found that loss of mucus from the afferent side of the filament was more pronounced than that on the efferent side. We also noticed such difference between the two sides (Table 1). Kobayashi ${ }^{20)}$ pointed out that mucus could be secreted from the gill within $15 \mathrm{~min}$ after Chattonella exposure. However, these results may have been flawed to some extent as the method used was not specifically aimed at preservation of mucus that was only loosely attached onto the surface of the gill. Half of the control fish showed mucus blockade on the afferent side, while one fish in the Chattonella-exposed group showed almost no mucus blockade in spite of a severe decrease in $\mathrm{PaO}_{2}$ (Table 1). Thus, some mucus was possibly secreted from the mucus cells during tissue processing or, on the contrary, some secreted mucus could have been lost during tissue processing. There are a few papers specifically devoted to the histological preservation of mucous coat of the gills. ${ }^{21-24)}$

\section{The Mechanism of Fish Kill by Chattonella}

We propose that the initial $\mathrm{PaO}_{2}$ drop during Chattonella exposure results from blockade of respiratory water flow through the gills by massive secretion of mucus and not from edema formation as previously proposed. This contention is based on the findings that (1) interfilamental spaces were often blocked by mucus at the time of $\mathrm{PaO}_{2}$ drop, but (2) branchial edema was not observed in the gills sampled at that time. Mucus covering the surface of the lamellae acts as a diffusion barrier as its diffusion constant is comparable to that of water, and would therefore constitute an additional unstirred layer through which oxygen must diffuse. ${ }^{25)}$ It may be more important for the secreted mucus to impair water flow through the lamellae by blocking the interfilamental spaces, thereby shunting inflowing respiratory water away from the gas exchange surface. It is true that Chattonella severely damaged the gills, causing epithelial separation in both secondary lamellae and filaments as well as several other types of lesions as demonstrated in experiment 1 . However, these alterations were hardly detectable at the time of $\mathrm{PaO}_{2}$ drop and therefore cannot be the cause of hypoxemia. Ishimatsu et $a l^{7,8)}$ found other physiological perturbations, such as acidosis and an elevation of plasma ions, becoming manifest toward the death. These may be related to destruction of the ion transport capacity caused by chloride cell dysfunctioning.

We currently speculate that oxygen radicals are involved 
in the release of mucus from the gills. There is increasing evidence for the production of oxygen radicals by Chattonella in resting conditions. ${ }^{26-32)}$ Oda et al. ${ }^{30)}$ reported that the concentration of hydrogen peroxide in medium increased 10 to 15 -fold after disruption of $C$. marina cells. Shimada et $a .^{27)}$ and Tanaka et $a l^{32)}$ reported evidence that superoxide $\left(\mathrm{O}_{2}^{-}\right)$was generated in small particles or "verruciform protrusions,"' located on the surface of $C$. antiqua cells. These structures were released from the cells when mucus from yellowtail gill was added to sea water. They interpreted the results as an indication of enhanced generation of $\mathrm{O}_{2}^{-}$in response to stimulation. Oxygen radicals are known to induce mucin secretion from mucus cells in guinea pig gallbladder ${ }^{33)}$ and rat gastric mucosa. ${ }^{34)}$ Thus, it is possible that oxygen radicals released from Chattonel$l a$ cells are responsible for mucus secretion from gill mucus cells observed in the present study. The release of oxygen radicals might be enhanced when cells are inhaled into the mouth and contact the surface of the gills or are mechanically stimulated by colliding against the branchial surface. Chattonella cells trapped within the mucus (Fig. 6C) may further aggravate the situation. It is also possible that part of the mucus was derived from Chattonella cells. Further studies are needed to test the hypothesis.

Acknowledgments We are grateful to the staff of the Aquaculture Laboratory, Nagasaki Prefectural Institute of Fisheries for their help in conducting this study, which was supported by a Grant-in-Aid for Scientific Research from the Ministry of Education, Science, Sports and Culture of Japan (04660208).

\section{References}

1) T. Okaichi: Red tide problems in the Seto Inland Sea, Japan, in "Red tides: biology, environmental science, and toxicology" (ed. by T. Okaichi, D. M. Anderson, and T. Nemoto), Elsevier, New York, 1989, pp. 137-142.

2) T. Matsusato and $H$. Kobayashi: Studies on death of fish caused by red tide. Bull. Nansei Reg. Fish. Res. Lab., 7, 43-67 (1974).

3) K. Yamaguchi, K. Ogawa, N. Takeda, K. Hashimoto, and T. Okaichi: Oxygen equilibria of hemoglobins of cultured sea fishes, with special reference to red tide-associated mass mortality of yellowtail. Nippon Suisan Gakkaishi, 47, 403-409 (1981).

4) M. Endo, T. Sakai, and A. Kuroki: Histological and histochemical changes in the gills of the yellowtail Seriola quinqueradiata exposed to the Raphidophycean flagellate Chattonella marina. Mar. Biol., 87, 193-197 (1985).

5) M. Endo, R. Foscarini, and A. Kuroki: Electrocardiogram of a marine fish, Pagrus major, exposed to red tide plankton, Chattonella marina. Mar. Biol., 97, 477-481 (1988).

6) T. Sakai, K. Yamamoto, M. Endo, A. Kuroki, K. Kumanda, K. Takeda, and T. Aramaki: Changes in the gill carbonic anhydrase activity of fish exposed to Chattonella marina red tide, with special reference to the mortality. Nippon Suisan Gakkaishi, 52, 1351-1354 (1986).

7) A. Ishimatsu, H. Maruta, T. Tsuchiyama, and M. Ozaki: Respiratory, ionoregulatory and cardiovascular responses of the yellowtail Seriola qunqueradiata to exposure to the red tide plankton Chattonella. Nippon Suisan Gakkaishi, 56, 189-199 (1990).

8) A. Ishimatsu, T. Tsuchiyama, M. Yoshida, M. Sameshima, M. Pawluk, and T. Oda: Effect of Chattonella exposure on acid-base status of the yellowtail. Nippon Suisan Gakkaishi, 57, 2115-2120 (1991).

9) T. Tsuchiyama, A. Ishimatsu, T. Oda, S. Uchida, and M. Ozaki: Effect of Chattonella exposure on plasma catecholamine levels in the yellowtail. Nippon Suisan Gakkaishi, 58, 207-211 (1992).

10) M. Shimada, T. H. Murakami, T. Imahayashi, H. S. Ozaki, T.
Toyoshima, and T. Okaichi: Effects of sea bloom, Chattonella anti$q u a$, on gill primary lamellae of the young yellowtail, Seriola quinqueradiata. Acta Histochem. Cytochem., 16, 232-244 (1983).

11) T. Toyoshima, H. S. Ozaki, M. Shimada, T. Okaichi, and T. H. Murakami: Ultrastructural alterations on chloride cells of the yellowtail Seriola quinqueradiata, following exposure to the red tide species Chattonella antiqua. Mar. Biol., 38, 101-108 (1985).

12) D. J. Speare and H. W. Ferguson: Fixation artifacts in rainbow trout (Salmo gairdneri) gills: A morphometric evaluation. Can. J. Fish, aquat. Sci., 46, 780-785 (1989).

13) J. F. Skidmore and P. W. A. Tovell: Toxic effects of zinc sulphate on the gills of rainbow trout. Wat. Res., 6, 217-230 (1972).

14) H. W. Ferguson: Systemic pathology of fish, Iowa State University Press, lowa 1989, p. 263.

15) J. Mallatt: Fish gill structural changes induced by toxicants and other irritants: A statistical review. Can. J. Fish. aquat. Sci., 42, 630-648 (1985).

16) S. Crespo, F. Padros, R. Sala, and M. J. Marlasca: Gill structure of cultured Salmo trutta fario related to sampling technique. Dis. aquat. Org., 4, 219-221 (1988).

17) A. Soivio and $\mathrm{H}$. Tuurala: Structural and circulatory responses to hypoxia in the secondary lamellae of Salmo gairdneri gills at two temperatures. J. comp. Phys., 145, 37-43 (1981).

18) J. Piiper and P. Scheid: Physical principles of respiratory gas exchange in fish gills, in "Gills" (ed. by D. F. Houlihan, J. C. Rankin, and T. J. Shuttleworth), Cambridge University Press, Cambridge, 1982, pp. 45-61.

19) J. N. Cameron: Models of gas exchange, in "The respiratory physiology of animals" (ed. by J. N. Cameron), Oxford University Press, New York, 1989, pp. 135-154.

20) H. Kobayashi: Some aspects on the secretion of gill mucus in red sea bream Pagrus major exposed to the red tide. Nippon Suisan Gakkaishi, 55, 553-557 (1989).

21) R. D. Handy and F. B. Eddy: The absence of mucus on the secondary lamellae of unstressed rainbow trout, Oncorhynchus mykiss (Walbaum). J. Fish Biol., 38, 153-155 (1991).

22) M. D. Powell, D. J. Speare, and J. F. Burka: Fixation of mucus on rainbow trout (Oncorhynchus mykiss Walbaum) gills for light and electron microscopy. J. Fish Biol., 41, 813-824 (1992).

23) M. D. Powell, D. J. Speare, and G. M. Wright: Comparative ultrastructural morphology of lamellar epithelial, chloride and mucous cell glycocalyx of the rainbow trout (Oncorhynchus mykiss) gill. $J$. Fish Biol, , 44, 725-730 (1994).

24) J. S. Lumsden, H. W. Ferguson, V. E. Ostland, and P. J. Byrne: The mucous coat on gill lamellae of rainbow trout (Oncorhynchus mykiss). Cell Tiss. Res., 275, 187-193 (1994).

25) G. R. Ultsch and G. Gros: Mucus as a diffusion barrier to oxygen: possible role in $\mathrm{O}_{2}$ uptake at low $\mathrm{pH}$ in carp (Cyprinus carpio) gills. Comp. Biochem. Physiol., 62, 685-689 (1979).

26) M. Shimada, N. Nakai, H. Goto, M. Watanabe, H. Watanabe, M. Nakanishi, S. Yoshimatsu, and C. Ono: Free radical production by the red tide alga, Chattonella antiqua. Histochemical Journal, 23, 362-365 (1991).

27) M. Shimada, S. Kawamoto, Y. Nakatsuka, and M. Watanabe: Localization of superoxide anion in the red tide alga Chattonella antiqua. J. Histochem. Cytochem., 41, 507-511 (1993).

28) T. Oda, T. Akaike, K. Sato, A. Ishimatsu, S. Takeshita, T. Muramatsu, and H. Maeda: Hydroxyl radical generation by red tide algae. Arch. Biochem. Biophys., 294, 38-43 (1992).

29) T. Oda, A. Ishimatsu, M. Shimada, S. Takeshita, and T. Muramatsu: Oxygen-radical-mediated toxic effects of the red tide flagellate Chattonella marina on Vibrio alginolyticus. Mar. Biol., 112, 505-509 (1992).

30) T. Oda, A. Ishimatsu, S. Takeshita, and T. Muramatsu: Hydrogen peroxide production by the red-tide flagellate Chattonella marina. Biosci. Biotech. Biochem., 58, 957-958 (1994).

31) K. Tanaka, S. Yoshimatsu, and M. Shimada: Generation of superoxide anions by Chattonella antiqua: Possible causes for fish death by 'Red Tide'. Experientia, 48, 888-890 (1992).

32) K. Tanaka, Y. Muto, and M. Shimada: Generation of superoxide anion radicals by the marine phytoplankton organism, Chattonella 
antiqua. J. Plankt. Res., 16, $161-169$ (1994).

$33)$ J. T. LaMont: Oxygen radicals stimulate gallbladder glycoprotein secretion, in "Mucus and related topics" (ed. by E. Chantler and N. A. Ratcliffe), The Company of Biologists Ltd, Cambridge, 1989, pp. 273-278.
34) H. Hiraishi, A. Terano, S. Ota, H. Mutoh, T. Sugimoto, M. Razandi, and K. J. Ivey: Oxygen metabolites stimulate mucous glycoprotein secretion from cultured rat gastric mucous cells. $A \mathrm{~m}$. J. Phys, 261, G662-G668 (1991). 